\title{
Direito e saúde mental: percurso histórico com vistas à superação da exclusão
}

Law and mental health: historical journey to overcome the exclusion

Derecho y salud mental: recorrido histórico para superar la exclusión

\author{
Ana Flávia Ferreira de Almeida Santana* \\ Tânia Couto Machado Chianca* \\ Clareci Silva Cardoso ${ }^{* * *}$
}

\begin{abstract}
Resumo
Este trabalho se trata de uma revisão narrativa da literatura para conhecer as informações históricas e teóricas disponíveis sobre as relaçóes entre crime e loucura. As modernas concepçóes de crime e de loucura constituíram espaços privilegiados de intervenção e controle social nos últimos dois séculos. Os manicômios judiciários e as medidas de segurança funcionam como instrumentos de controle social. Em nome da defesa social, tornou-se possível a aplicação de métodos de correção, tratamento e ressocialização dos indivíduos, e o nível de periculosidade pode ser extinto pelos mecanismos de controle e vigilância. A criação de uma categoria social "louco-criminoso" desenvolveu um complexo aparelho jurídico-institucional voltado para o tratamento clínico e para a contenção de comportamentos ditos anormais. Conclui-se que a realidade social dos manicômios judiciários e das medidas de segurança necessita ser compreendida, assim como as atuais concepçóes e formas de atuação frente à criação da relação entre o crime e a loucura.

Palavras-chave: crime, loucura, manicômio judiciário, processo saúde-doença
\end{abstract}

\section{Abstract}

It is a narrative literature revision to search historical and theoretical information available about crime and mental insanity relations.

\footnotetext{
Texto recebido em dezembro de 2010 e aprovado para publicação em abril de 2011.

Doutoranda em Enfermagem pela Escola de Enfermagem da UFMG, Psicóloga do Tribunal de Justiça de Minas Gerais. E-mail: anaflaviaffa@yahoo.com.br.

** Doutora em Enfermagem, professora associada do Departamento de Enfermagem Básica da Escola de Enfermagem da Universidade Federal de Minas Gerais. E-mail: taniacmc@enf.ufmg.br.

${ }^{* * *}$ Doutora em Saúde Pública-Epidemiologia, professora adjunta da Universidade Federal de São João del-Rei, Grupo de Pesquisa em Epidemiologia e Avaliação de Novas Tecnologias em Saúde UFSJ/CNPq. E-mail: clarecicardoso@yahoo.com.br.
} 
The modern conceptions of crime and mental insanity have been constituted privileged spaces of intervention and social control for over two centuries. The Judiciary Mental Hospitals and the security measures are instruments of social control. On behalf of social protection, it was feasible the enforcement of correctional methods, treatment and individual's socialization and their level of dangerousness could be extinguished through mechanisms of control and surveillance. The creation of a social category, the "criminally-insane", developed a complex judicial institute focused on clinical treatment and restraining of a behavior known called abnormal. Finally, the social reality of Judiciary Mental Hospitals and surveillance measures need to be understood, as well as the current conceptions and actions towards the conception of the relation between crime and mental insanity. Surveillance measures need to be understood, as well as the current conceptions and actions towards the conception of crime and mental insanity relationship.

Keywords: crime, mental insanity, judiciary mental hospitals, health-disease process.

\section{Resumen}

Se trata de una revisión narrativa de la literatura para la búsqueda de información histórica y teórica disponible sobre las relaciones entre el crimen y la locura mental. Las concepciones modernas de la delincuencia y la locura mental se han constituido en espacios privilegiados de intervención y control social en los dos últimos siglos. El Poder Judicial de hospitales psiquiátricos y las medidas de seguridad son instrumentos de control social. En nombre de la protección social se hizo posible la aplicación de métodos correccionales, tratamiento y resocialización de los individuos y su nivel de peligrosidad pudo ser extinguido a través de mecanismos de control y vigilancia. La creación de una categoría social, el "criminalmente insano", desarrolló un complejo aparato jurídicoinstitucional que se centró en el tratamiento clínico y en el control de comportamientos denominados de anormales. Se concluye que la realidad social de los hospitales psiquiátricos del Poder Judicial y de las medidas de vigilancia deben ser comprendidas tal y como hoy se entienden, así como las acciones que enfrentan la relación entre delincuencia y locura mental.

Palabras clave: delincuencia, locura mental, hospitales psiquiátricos del Poder Judicial, proceso salud-enfermedad. 


\section{Introdução}

N a última década, profissionais da Psicologia e do Direito têm discutido a falta de garantia dos direitos constitucionais de acesso universal às ações e serviços de promoção, proteção e recuperação da saúde dos portadores de sofrimento mental que cometeram um crime e foram submetidos à medida de segurança baseada no modelo de internação manicomial. A prática desses profissionais vem apontando que a proposta da Reforma Psiquiátrica, de desconstrução do agir institucional e da segregação, não tem alcançando esses pacientes que estão sob custódia do Estado em manicômios judiciários (Barros, 2003; Amarante, 1995). A ideia da atenção psicossocial, que leva em consideração o sujeito pertencente a um grupo familiar e social, assim como objetiva a reinserção social com a consequente recuperação da cidadania, precisa ser alvo de discussão (Amarante, 1994; Costa-Rosa, 2000).

Do ponto de vista jurídico, o portador de sofrimento psíquico, ao cometer um crime, não é considerado autor do ato, uma vez que é considerado incapaz de distinguir o caráter ilícito das próprias ações. Nesses casos, a regra determina a absolvição com aplicação de medida de segurança (MS), com prazo indeterminado. A MS tem caráter preventivo e assistencial, podendo ser cumprida em regime ambulatorial ou internação em manicômio judiciário, para proteção da sociedade e do próprio paciente contra a ameaça presumida da doença mental (Brasil, 2001).

Os manicômios judiciários, instituições destinadas a custodiar e a tratar portadores de sofrimento mental que estão sob a guarda da justiça, têm características tanto de presídio como de asilo. A dupla vertente caracteriza a sobreposição de um espaço prisional e asilar, penitenciário e hospitalar. Dentro do que Carrara (1998) nomeia de "ambivalência como marca distintiva e a ambiguidade como espécie", o que fica como inequívoco é o conflito entre a dupla função, somada às caricaturas mais estigmatizadas socialmente, o louco e o criminoso (Carrara, 1989; Goffman, 1974).

O conhecimento existente sobre o tema é incipiente e, em sua maioria, está relacionado ao paradigma da periculosidade. A carência de estudos e de conhecimento aponta para a necessidade de sistematizar e realizar novos estudos que possam contribuir para a atualização sobre o tema, além de favorecer avanços na área (Baságlia, 1985; Wagner \& King, 
2005).

Assim, este estudo visa a revisar a literatura sobre a história e as relações estabelecidas entre os temas crime e loucura.

\section{Metodologia}

Trata-se de revisão narrativa da literatura para sintetizar o conhecimento sobre a história das relaçôes entre crime e loucura a partir da avaliação crítica de referências disponíveis em bases de dados indexadas. Além de artigos, foram também incluídos livros-texto sobre os temas, teses e dissertações disponíveis.

Foi realizada busca nas bases de dados eletrônicas da Med Line, Scielo, Lilacs, Cochrane e Biblioserver, utilizando-se as seguintes palavras-chave: "forensic psychistry"; "dangerousness"; "medida de segurança"; "manicômio judiciário", "inimputabilidade" e "hospital psiquiátrico". As publicações foram selecionadas pelo título e ou resumo. Não foi definido limite de data, idioma ou tipo de estudo. $\mathrm{O}$ material foi submetido à leitura crítica e sintetizado em dois temas-chave: aspectos históricos da criminalidade e a relação entre o crime e a loucura.

\section{Resultados e discussão}

$\mathrm{Na}$ busca nas bases de dados eletrônicas selecionadas, encontraram-se tanto artigos como livros-texto, teses e dissertações que podem ajudar a entender como o crime e a loucura têm sido tratados no Brasil.

Com base na leitura crítica do material encontrado, definiu-se por dois temas que imergiram: os aspectos históricos da criminalidade e a relação estabelecida entre os temas crime e loucura, e que podem ajudar a mostrar a realidade social dos manicômios judiciários mantidos no Brasil, com suas características de instituições híbridas e que agregam funções tanto hospitalares como prisionais. Uma realidade que precisa ser compreendida para que estratégias de superação dos problemas possam ser realizadas.

\section{Aspectos históricos da criminalidade}

As condutas contrárias ao interesse coletivo (como os crimes) colocam em risco aspectos característicos da civilização, podendo inviabilizar a possibilidade do convívio social (Freud, 1997). Daí a necessidade de um contrato, firmado com base na expressão da vontade da comunidade, delimitando os sacrifícios individuais que devem ser feitos em prol do bem-estar coletivo. As ações 
proibidas a cada indivíduo precisam, então, ser controladas de acordo com o contrato social estabelecido. Um poder de controle é formado nos moldes do "direito", que expressa as normas a serem seguidas e atua ativamente em prol da manutenção da harmonia social (Foucalt, 1987, 2001; Passetti, 1999).

$\mathrm{Na}$ história das penas, traçada por Foucault (1987), a manifestação do poder de vigiar e punir as transgressões das regras do "direito superior" sobre as vontades individuais seguiram os momentos históricos vividos pelas sociedades, obedecendo aos sistemas econômicos, de produção e de governo vigentes.

O suplício do corpo, com sua função jurídico-política, foi utilizado na época medieval como um ritual público de dominação dos indivíduos. Um ritual político para demonstração do poder de punição e de controle social. $\mathrm{O}$ suplício tinha ainda como objetivo a convocação do povo como testemunha da vingança do soberano sobre aquele que, pelo crime, o injuriou (Foucalt, 1987; Almeida, 2004).

A lei de talião, cujos primórdios datam de 1780 a.C. na Babilônia, tinha como objetivo sacrificar a parte do corpo do criminoso que fora utilizada para cometer o crime, como forma de impedir a reincidência. Apontava para a necessidade de prevenção contra o crime (Bobbio, 2000; Comparato, 2007).

As penas passaram do suplício do corpo à suspensão dos direitos individuais. No Século das Luzes, o poder de punição precisou ser desvinculado da vingança do soberano sobre os súditos, por meio da dissociação do arbítrio do poder monárquico. A reforma do direito criminal sofreu um remanejamento nas estratégias do poder de punir. Uma nova "economia política" do poder de punir foi instaurada, sendo o conhecimento científico uma tática de dominação (Foucalt, 1987; Rego, 2004; Fontana-Rosa, 2006).

Uma abordagem legalista para a aplicação das penas, baseada em ideais humanitários, garantiu a individualização e proporcionalidade entre a pena e o delito. Surgiu, então, a Escola Clássica do Direito Penal, que estruturou uma noção de crime sob os postulados do livre-arbítrio e responsabilidade moral. O livre-arbítrio era derivado da capacidade de discernimento do homem. A responsabilidade moral considerava o homem capaz de prever, conscientemente, a moralidade ou não dos seus atos (Almeida \& Guerra, 2000; Savino Filho, 2000; Koerner, 2006).

A moderna tecnologia de punir foi caracterizada pelas relações de poder investidas na docilidade e utilidade das forças corporais. As relações de controle no sistema punitivo passaram a ser engendradas sobre o poder das 
classes dominantes, que fizeram da alma uma prisão do corpo dos condenados (Foucalt, 1987).

A nova definição do poder de punir era concebida como sendo função da sociedade, devendo ser exercida sobre todos os indivíduos na mesma medida. No entanto, ficou submetida às diferenças de julgamentos disciplinares, dando origem ao nascimento das prisōes, consideradas por Foucault (1987) como "pena das sociedades civilizadas". As relações de dominação do sistema punitivo foram orientadas pelo sistema produtivo, fazendo dos corpos uma força produtiva submetida ao poder econômico do corpo (Koerner, 2006).

Em meados do século XIX, com a instituição da ordem burguesa, fizeramse necessários recursos penais que garantissem o estabelecimento das novas diretrizes políticas, econômicas e jurídicas. O desenvolvimento da filosofia positivista e dos estudos biológicos e sociológicos deu origem à Escola Positiva do Direito Penal. Novos caminhos para a compreensão do crime, que vinha apresentando altas taxas e crescente reincidência, começaram a ser propostos. A Escola Positiva vinculou-se a uma metodologia empírica, sustentada no modelo causal explicativo e indutivo (Calhau, 2008; Wacquant, 2008).

Essa escola tinha, na figura do criminoso, com seus comportamentos e personalidade, o seu objeto privilegiado de estudo. As avaliações da realidade biopsíquica e social dos delinquentes fizeram-se necessárias para o diagnóstico do nível de perigo social apresentado pelo sujeito. A periculosidade, fruto da inaptidão para o convívio social, precisava ser prevenida e tratada. O corpo social necessitava de defesa contra a ação do delinquente, priorizando os interesses e defesa do grupo social (Ramos \& Cohen, 2002; Almeida, 2004).

Os adeptos dessa Escola Positivista apresentavam uma concepção cientificista e individualizada do homem delinquente, considerando a singularidade do criminoso. Assim como fizeram os alienistas, que deram aos loucos status de inocentes passíveis de tratamento, nessa abordagem filosófica, o direito criminal passou a tratar os criminosos como irresponsáveis por seus atos. Apesar de terem sido destituídos da responsabilidade moral pelos crimes, a responsabilidade pelo perigo que representavam para a sociedade foi considerada inerente aos "loucos" (Carrara, 1998).

Seriam necessários novos métodos no exame científico do crime, substituindo as interpretações metafísicas e estabelecendo um experimentalismo sistemático. A classificação científica dos sujeitos delinquentes, feita de acordo com as causas da ação criminosa, seria a mais adequada para o estabelecimento de intervenção penal (Beccaria, 1999; Flauzina \& Barreto, 2004). 
O índice de criminalidade passou a ser determinado, estimando-se a expectativa individual de reincidência. $\mathrm{O}$ objetivo de tal avaliação era o estabelecimento do índice de perigo e temibilidade que o sujeito apresentava para o corpo social. Em nome da proteção social, a Escola Positiva pregava a eliminação física ou o segregamento absoluto e eterno para o sujeito, independentemente do cometimento e gravidade do crime (Shecaira, 2002).

\section{A relação entre o crime e loucura}

As modernas concepções de loucura e crime são resultados de um processo que vem se desenvolvendo há mais de dois séculos. No final do século XIX, questôes referentes ao crime e ao criminoso foram alvo de reflexões sistemáticas ensejadas pelo aumento significativo no número de crimes nas grandes cidades dos países ocidentais, bem como pela crise atravessada pelo liberalismo (Carrara, 1998).

O desenfreado crescimento populacional provocado pelo processo de urbanização das metrópoles, as exigências da industrialização e os moldes de organização do sistema capitalista são alguns dos fatores apontados como agravantes dos conflitos sociais. Paralelo às inevitáveis tensões sociais provocadas pelo processo de industrialização e urbanização, a formação do fenômeno social chamado "meio delinquencial fechado" atingiu principalmente os infratores das classes populares e fez parte da construção do novo perfil assumido na criminalidade (Foucault, 1987).

A marginalização imposta pela prática prisional possibilitou a organização e especialização do "crime". Aqueles que foram submetidos à reclusão e ao absoluto desligamento de seu meio social tiveram como destino a irreversibilidade de sua história como delinquente. $O$ fenômeno da reincidência apareceu, então, como consequência de uma trajetória social, que passou a ser sem retorno, e deu luz à concepção da delinquência "enquanto manifestação de uma natureza individual anômala, de um psiquismo perturbado pela doença”" (Carrara, 1998, p. 64).

Dentro do novo perfil assumido pela criminalidade no meio urbano, a reincidência atuou também como prerrogativa ao aparecimento da "polícia científica”, consequência da modernização das técnicas de controle e repressão nos aparelhos policiais. E, além do objetivo de atuação sobre a criminalidade emergente, a modernização da polícia se expandiu para o tecido social, atingindo principalmente as camadas menos favorecidas da população, alvo de maior necessidade de contenção e disciplinarização (Paim, 1997). 
A emergente reflexão sobre o crime tinha também como pano de fundo o individualismo como questão política. A liberdade, ponto-chave no discurso das sociedades liberais, vinha alimentando certo excesso de individualismo, tendo como consequência transgressões criminosas e político-ideológicas extremistas. A desigualdade social foi colocada à mostra, tendo como resposta a atuação popular, colocando em risco a ordem social. A ordem liberal, propagadora da igualdade jurídica e da liberdade individual, não tinha recursos suficientes para lidar com a realidade das diferenças sociais existentes. Fazia-se necessário, então, uma reforma institucional que garantisse leis convenientes ao fortalecimento do Estado e de instrumentos aplicáveis ao controle social (Carrara, 1998; Wacquant, 2008).

Assim, no início do século XIX, os alienistas foram convocados pelo aparelho judiciário a participar de processos que envolviam crimes que contradiziam o que era considerado como de "natureza humana". Eles negavam os princípios básicos do contrato social e a existência da racionalidade intrínseca ao ser humano, considerando que os crimes não eram praticados por indivíduos enquadrados nos clássicos perfis da loucura. Os alienistas passaram a atuar em prol do bom funcionamento da máquina judiciária, na resolução de ações criminosas cometidas por indivíduos que aparentemente não eram loucos (Mattos, 1999; Dutra, 2000).

Nesses casos, por meio do trabalho dos alienistas, foi aberto espaço para a aproximação entre o crime e a loucura, suscitando a ideia da existência de uma relação direta entre os dois. O conceito nosológico de monomania, utilizado por psiquiatras franceses no início do século XIX, exerceu papel importante no desenvolvimento da discussão, que colocava o crime como manifestação de uma doença mental (Darmon, 1991; Barreto, Valença, Josef \& Mecler, 2004).

As monomanias eram compreendidas como "delírio parcial", espécie de delírio direcionado a apenas uma ideia. Por serem parciais, os delírios monomaníacos possibilitavam aos sujeitos total lucidez nos aspectos da vida não relacionados ao objeto do delírio. Isso fazia dos monomaníacos ainda mais perigosos, uma vez que a doença deles poderia passar despercebida pela sociedade, tornando incompreensíveis os crimes praticados por eles (Bercherie, 1980; Mattos, 1999).

A concepção de loucura como alienação mental foi forjada, não tendo necessariamente que ser caracterizada pelo delírio. Por outro lado, as monomanias suscitaram a submissão da consciência aos desejos e impulsos incontroláveis dos doentes, que passaram a ter suas ações consideradas como 
automáticas (Savino Filho, 2000; Fontana-Rosa \& Cohen, 2006).

A loucura deixou de manter o enigma do mundo interior do homem, fazendo com que seus sinais mais claros não fossem publicamente reconhecidos. A noção de loucura moral assumiu o lugar da ausência de identidade do indivíduo, passando a considerar um processo congênito ou hereditário que acompanha o sujeito do nascimento até a morte. Sendo assim, uma doença invisível, imprevisível e sem possibilidade de cura, não poderia assumir outro caráter que fugisse ao perigo iminente (Badaró, 1972; Carrara, 1998).

Em meados do século XIX, a teoria da monomania passou a concorrer com a noção da chamada degeneração. Ambas as teorias pretendiam abordar, de maneira diferente, os crimes "irracionais", que não têm como fundamento o delírio clássico, mas que têm por premissa a loucura congênita e incurável (Rezende, 1993; Carrara, 1998).

A doutrina da degeneração teve como postulados básicos a unicidade do ser humano e hereditariedade mórbida. O primeiro partia da premissa da relação imediata entre o físico e o moral. O segundo considerava a possibilidade da transmissão de características mórbidas dos ascendentes para os descendentes. O sistema nervoso foi responsabilizado pelas perturbações físico-morais do homem e assumiu o papel de unificador etiológico das perturbações mentais (Carrara, 1998; Mattos, 1999).

A ideia da degeneração possibilitou a transformação do crime em objeto de estudo, numa abordagem psicopatológica. $\mathrm{O}$ comportamento criminoso ganhou status de manifestação degenerativa, fazendo do criminoso um doente, sem, no entanto, enquadrá-lo totalmente na figura do louco. A degeneração "patologizou" o crime e fez dele uma disfunção orgânica (Bercherie, 1980).

O crime, assim como a loucura, assumiu caráter de comportamento característico do ser humano. O fenômeno do atavismo, caracterizado pela noção de formas humanas inferiores, foi usado como possibilidade de explicação para o crime. A classificação de criminosos natos apareceu, então, como um tipo regressivo do ser humano. Foi delineada a partir de indicadores da animalidade original, sendo marcada por estigmas que apareciam tanto no corpo como na alma do criminoso. Esses estigmas seguiram pressupostos anatômicos, fisiológicos, psicológicos, fisionômicos e até mesmo de fenômenos naturais (Cesare, 1887; Bruno, 1977; Alvarez, 2002).

Manifestações patológicas, variações ou inferioridades biológicas mostravam a irresponsabilização de sujeitos desviantes das normas sociais, bem como funcionavam como justificativa para as diferenças existentes entre os homens. 
Diante de tais circunstâncias, a relação criada entre loucura e criminalidade destacou o caráter perigoso e violento dos doentes criminosos. Essa era justificativa para a necessidade de tratamento deles e, consequentemente, para impor a importância e especificidade do trabalho dos alienistas (Cohen, 1981; Peres, 2007).

Profissionais de diversas áreas da saúde, ao assumirem a loucura como objeto de estudo, deixaram de atuar exclusivamente com a cura e tratamento da saúde dos indivíduos. Passaram a atuar, auxiliando o Poder Judiciário, como medidores da responsabilidade jurídica de cada indivíduo, para neutralizar os sujeitos que representassem perigo para a harmonia da sociedade. A atuação dos alienistas fez com que a Justiça deixasse de olhar para os indivíduos como sujeitos de direito para percebê-los como homens-objeto, passíveis de tratamento e correção (Foucault, 2001).

No momento em que os alienistas assumem um papel nos tribunais, as respectivas disciplinas referentes à atuação de médicos e juízes sofrem uma progressiva tendência à indistinção. A psiquiatria passa a exercer poder na sociedade ao se afirmar como ciência dos anormais. Os alienistas exploraram o conceito de periculosidade, utilizado pela legislação penal para o estabelecimento das sanções penais aplicadas aos doentes mentais (Paim, 1981, 1998; Almeida, 2004).

Nem louco nem lúcido, nem enfermos nem sãos, os doentes mentais apresentavam características do ser humano que ameaçavam as instituições liberais, bem como a possibilidade de funcionamento das engrenagens da Justiça. Esse problema encontrou paliativo na construção dos manicômios judiciais, que, além de solução para a segregação de certos tipos de alienados, serviu como limite para os conflitos existentes entre moral e ciência (Alvim, 1997; Carrara, 1998).

O duplo objetivo dos manicômios judiciais, custodiar e tratar, teoricamente, não foi motivado por um sistema punitivo com promessa de melhores condições de assistência e tratamento para os alienados submetidos às restrições jurídicas. Por sua vez, essas instituições não puderam oferecer aos seus internos nada além de sua inerente ambiguidade (Andreucci, 1981; Jacobina, 2004).

Os manicômios judiciários são instituições totais, como as descritas por Goffman (1974), que colocam uma barreira quase que impenetrável entre o internado e o mundo externo, provocando a deformação pessoal decorrente da perda do conjunto de fatores determinantes da identidade e assegurando profunda ruptura com os papéis sociais anteriores (Carrara, 1998; Andrade, 


\section{1).}

Em função da influência de todas as questões trazidas pelo Movimento da Reforma Psiquiátrica, Fernanda Otoni Barros, psicóloga do Tribunal da Justiça do Estado de Minas Gerias, ao final do ano de 1999, concluiu uma pesquisa que teve como objetivo mapear os processos criminais em que os autores eram portadores de sofrimento psíquico. Em função da pesquisa, hospitais de custódia e tratamento foram visitados e revelaram a já conhecida violência contra os direitos humanos daqueles sujeitos.

Tal pesquisa deu origem a um projeto piloto, "Projeto de Atenção Interdisciplinar ao Paciente Judiciário" (PAI-PJ), que foi apresentado à Corregedoria do Tribunal de Justiça de Minas Gerais. O acompanhamento, a mediação entre o tratamento e o processo jurídico com o objetivo de inserção social foram os focos do trabalho apresentado. Originado de uma ação coletiva do Poder Judiciário, Rede de Saúde Pública do Estado de Minas Gerais e sociedade, o projeto PAI-PJ foi aprovado e implantado no ano de 2000 pelo TJMG, sendo, em 2001, transformado no Programa de Atenção Integral ao Paciente Judiciário Portador de Sofrimento Mental Infrator, por meio da Portaria Conjunta no 25/2001 (Barros, 2003).

O programa tem como objetivo proporcionar aos doutos juízes subsídios técnicos em relação a pacientes que estejam sob suspeita de insanidade mental ou em cumprimento de medida de segurança. Trabalhando com uma equipe multidisciplinar, o PAI-PJ pretende acompanhar integralmente o portador de sofrimento mental em todas as fases do seu processo criminal, desconstruindo o mito da periculosidade e promovendo recursos tanto para o tratamento do sofrimento mental como para a inserção social do sujeito (Barros, 2003).

A possibilidade de tratamento e cuidado dos pacientes em cumprimento de medida de segurança, em regime ambulatorial, tem sido viabilizada pela proposta de trabalho do PAI-PJ, em concordância com o preconizado pelo Movimento da Reforma Psiquiátrica. Outras experiências bem-sucedidas, como o Programa de Atenção Integral ao Louco Infrator de Goiás, seguem os princípios básicos preconizados pelo trabalho do TJMG.

\section{Considerações finais}

Ainda nos dias de hoje, os manicômios judiciários são mantidos no Brasil com todas as características de uma instituição híbrida, integrando e misturando funções de uma instituição hospitalar e prisional. Pesquisas 
revelam sério comprometimento na qualidade de vida e situação psicossocial dos pacientes em cumprimento de medida de segurança em manicômio judiciário (Santana, Chianca \& Cardoso, 2009).

Historicamente, as medidas de segurança foram aplicadas a partir de uma cultura de exclusão, de temor daquilo que a loucura anuncia e representa para a sociedade, que acaba por se proteger, "autossegurar-se" por meio do exílio perpétuo no manicômio judiciário (Delgado, 1992).

No entanto, a medida jurídica só atingirá seu fim público de zelar pelos direitos desses cidadãos ao convocá-los a responder por seus atos diante do corpo social. Ser inimputável, não ter direito de autoria das próprias palavras e ações, ser condenado ao sepulcro do silêncio no exílio social eterno não parece cumprir as exigências impostas pelos direitos humanos. Ao contrário, ser convocado a responder pelo crime, assumir a responsabilidade pelos próprios atos, apresenta para o sujeito a dimensão da lei, um instrumento que pode operar no sentido de uma construção de convivência com o social no espaço público (Barros, 2003).

A implicação e a responsabilização pelo ato cometido têm sido preconizadas por alguns autores como uma possibilidade para o sujeito. Ao contrário do preconizado pela atual prática jurídica, a sentença de inimputabilidade decretada aos pacientes age como uma violação. Ser inimputável significa não ter direito à palavra e à ação. Inviabiliza a possibilidade que o sujeito teria de refazer seu ato, de produzir um sentido por meio da palavra e, consequentemente, localizar o excesso de sua angústia. Ao ser convocado pela Justiça a responder por seus atos, responsabilizando-se por eles, o sujeito terá a oportunidade de construir um projeto de convivência no âmbito social como qualquer cidadão o faz. O ato jurídico, o chamado pela responsabilização, atua como operador clínico, extremamente necessário à condução do tratamento do paciente. Portanto a mediação entre a clínica, o social e o ato jurídico é necessária à organização subjetiva dos pacientes (Rezende, 1993; Barros, 2003).

A realidade social dos manicômios judiciários necessita ser compreendida, assim como as atuais regras de formação para lidar com o conjunto de relações existentes entre o crime e a loucura. A proposta da Reforma Psiquiátrica, desconstrução do agir institucional e da segregação, precisa alcançar os pacientes que estão sob custódia do Estado em manicômios judiciários. As conquistas alcançadas pelo Movimento da Reforma Psiquiátrica podem contribuir para a construção 
de um caminho para a quebra do estigma da periculosidade do louco infrator, bem como para a viabilização de políticas compatíveis com um tratamento digno e humanitário para tais pacientes (Lobosque, 1999; Barreto, 1999).

Faz-se necessário esforço para implantar estratégias de mudanças e articulação daqueles que fazem do discurso jurídico, da saúde pública e da área de saúde mental uma prática social. Tais discursos, envolvidos nos modos particulares e contraditórios da relação existente entre crime e loucura, necessitam ser considerados ativamente na atual construção das práticas sociais que envolvem a inimputabilidade, periculosidade e inserção social do "louco infrator".

\section{Referências}

Almeida, C. C. P., Guerrero, H. V. \& Barros, H. L. (2000). Análise crítica do instituto das medidas de segurança. Revista da Pesquisa \& Pós-graduação, $2(2), 46-50$.

Almeida, C. C. P. (2004). Inimputabilidade, periculosidade e medidas de segurança: o enfoque jurídico da atual intervenção penal frente aos problemas de saúde mental. Dissertação de Mestrado, Faculdade de Direito, Universidade Federal de Minas Gerais, Belo Horizonte.

Alvarez, M. C. (2002). A criminologia no Brasil ou como tratar desigualmente os desiguais. Revista de Ciências Sociais, 45 (4), 677-704.

Alvim, R. C. M. (1997). Uma pequena história das medidas de segurança. São Paulo: IBCCRIM.

Amarante, P. (1994). Psiquiatria social e reforma psiquiátrica. Rio de Janeiro: Fiocruz.

Amarante, P. (1995). Loucos pela vida: a trajetória da reforma psiquiátrica no Brasil. Rio de Janeiro: Escola Nacional de Saúde Pública.

Andeucci, R. A. (1981). Manicômio judiciário e medidas de segurança alternativas. Revista do Conselho Penitenciário do Distrito Federal, 18 (43), 53-61.

Andrade, H. C. (2001). Das medidas de segurança. Tese de Doutorado, Faculdade de Direito, Universidade Federal de Minas Gerais, Belo Horizonte. 
Badaró, R. (1972). Inimputabilidade, periculosidade e medidas de segurança. São Paulo: Juriscredi.

Barreto, B. A., Valença, A. M., Jozef, F. \& Mecler, K. (2004). Periculosidade e responsabilidade penal na esquizofrenia. J. Bras. Psiquiat., 53 (5), 302-308.

Barreto, F. P. (1999). Reforma Psiquiátrica e Movimento Lacaniano. Belo Horizonte: Itatiaia.

Barros, F. O. (2003). Democracia, liberdade e responsabilidade: o que a loucura ensina sobre as ficções jurídicas. In: Conselho Federal de Psicologia (Org.). Loucura ética e política: escritos militantes. (pp. 112-136). São Paulo: Casa do Psicólogo.

Baságlia, F. (1985). A instituição negada: relato de um hospital psiquiátrico. Rio de Janeiro: Graal.

Beccaria, C. (1999). Dos delitos e das penas. Rio de Janeiro: Ediouro.

Bercherie, P. (1980). Les fondements de la clinique. Paris: Navarin.

Bobbio, N. (2000). O futuro da democracia. São Paulo: Paz e Terra.

BRASIL. (2001). Código Penal do Brasil. (39a ed.). São Paulo: Saraiva.

Bruno, A. (1977). Perigosidade criminal e medidas de segurança. Rio de Janeiro: Editora Rio.

Calhau, L. B. (2004). Cesare Lombroso: criminologia e a Escola Positiva de Direito Penal. Porto Alegre: Ed. Rev. Síntese de Direito Penal e Processual Penal.

Carrara, S. (1998). Crime e loucura: o aparecimento do manicômio judiciário na passagem do século. Rio de Janeiro: Eduerj.

Carrara, S. L. (1989). Casos e acasos: o crime de um certo Custódio e o surgimento do Manicomio Judiciário no Brasil. Cadernos IMS, 3 (1), 71-107.

Cesare L. (1887). L'Homme Criminel. Paris: Félix Alcan.

Cohen, C. (2006). Medida de segurança. In: Cohen, C. et alii. Saúde mental, crime e justiça. (pp. 123-129). São Paulo: Edusp.

Comparato, K. (2007). A afirmação histórica dos direitos humanos. São Paulo: Saraiva.

Costa-Rosa, A. (2000). O modo psicossocial: um paradigma das práticas substitutivas ao modelo asilar. In: Amarante, P. Ensaios: subjetividade, saúde mental, sociedade. (pp. 141-194). Rio de Janeiro: Fiocruz. 
Darmon, P. (1991). Médicos e assassinos na Belle Époque. Rio de Janeiro: Paz e Terra.

Delgado, P. G. (1992). As razóes da tutela: psiquiatria, justiça e cidadania do louco no Brasil. Rio de Janeiro: Te Corá.

Dutra, M. C. (2000). As relações entre psicose e periculosidade: contribuições clínicas da concepção psicanalítica da passagem ao ato. Rev. Latinoam. Psicopat. Fund., 3 (4), 59-79.

Flauzina, A. L. P., Barreto, F. C. O. \& Grosner, M. Q. (2004). A liberdade nas escolas penais. Rev. Fund. Super. Minist. Publi.Distrit. Fed., 12 (23), 58-64.

Fontana-Rosa, J. C. \& Cohen, C. (2006). Psicopatologia forense na esfera penal. In: Cohen, C. et alii. Saúde mental, crime e justiça. (pp. 109-118). São Paulo: Edusp.

Foucault, M. (1987). Vigiar e punir: nascimento da prisão. Petrópolis: Vozes.

Foucault, M. (2001). Os anormais. São Paulo: Martins Fontes.

Freud, S. (1997). O mal-estar na civilização. Rio de Janeiro: Imago.

Goffman, E. (1974). Manicômios, prisôes e conventos. São Paulo: Perspectiva.

Jacobina, P. V. (2004). Direito penal da loucura: medida de segurança e Reforma Psiquiátrica. Rev. Direito Sanit., 5 (1), 67-85.

Koerner, A. (2006). Punição, disciplina e pensamento penal no Brasil do século XIX. Lua Nova, 68, 205-242.

Lobosque, A. M. (1999). Principios para uma clínica antimanicomial e outros escritos. Belo Horizonte: Itatiaia.

Mattos, V. (1999). Trem de doido: o direito penal e a psiquiatria de mãos dadas. Belo Horizonte: UNA.

Paim, I. (1998). Estudos psiquiátricos. Campo Grande: Solivros.

Paim, I. (1981). Meio século de medida de segurança. Rev. ABP, 3 (8), 159163.

Paim, I. (1997). A crueldade da medida de segurança. J. Bras.Psiquiat., 46 (10), 515-521. 
Passetti, E. (1999). Sociedade de controle e abolição da punição. Perspectiva, 13 (3), 56-66.

Peres, M. F. T. (1997). A estratégia da periculosidade: psiquiatria e justiça em um hospital de custódia e tratamento. Dissertação de Mestrado, Instituto de Saúde Coletiva, Universidade Federal da Bahia, Salvador.

Ramos, M. R. R \& Cohen, C. (2002). Considerações acerca da semiimputabilidade e inimputabilidade penais resultantes de transtornos mentais e de comportamento. Rev. Brasileira de Ciências Criminais, 10 (39), 215-230.

Rego, I. P. (2004). Sociologia da prisão. Soc. Estado, 19 (1), 227-233.

Rezende, B. V. R. G. (1993). Uma contribuição ao estudo da periculosidade. Rev. Conselho de Criminologia e Politica Criminal, 6 (2), 85-109.

Santana, A. F. F. A., Chianca, T. C. M. \& Cardoso, C. S. (2009). Qualidade de vida de pacientes com esquizofrenia internados em hospital de custódia. Jor. Bras. Psi., 58 (3), 187-194.

Savino Filho, C. (2000). Evolução do direito penal: comentários. Rio de Janeiro: Ed. Rev. de Direito do TJRJ.

Shecaira, S. S. (2002). Teoria da Pena. São Paulo: Revista dos Tribunais.

Wacquant, L. (2008). O lugar da prisão na nova administração da pobreza. Novos estud. - Cebrap, 80, 9-19.

Wagner. L. C. \& King, M. (2005). Existential needs of people with psychotic disorders in Porto Alegre, Brazil. The British Journal of Psychiatry, 186, 141145 . 